\title{
La información diacrónica en el Diccionario de la Lengua Española de la Real Academia (Vigésima Primera Edición) ${ }^{1}$
}

\author{
Laura del Barrio Estévez \\ Sergio Torner Castells \\ Universidad Autónoma de Barcelona
}

Todo diccionario responde al intento de construir un posible modelo del léxico de una lengua. Cualquier modelo es una abstracción y, como tal, es una simplificación de una realidad harto más compleja. Al reducir la riqueza del léxico a las páginas de un diccionario se obtendrá inevitablemente una imagen parcial e incompleta que no reflejará nunca con exhaustividad la información asociada a cada pieza léxica. Cuando el lexicógrafo se enfrenta a la tarea de elaborar un diccionario debe decidir a qué aspectos históricos, semánticos, gramaticales, estilísticos y dialectales va a dar cabida en su obra, y, para ello, necesita criterios rigurosos que le permitan resolver los problemas concretos que cada palabra suscita. De la elección de estos criterios y de su aplicación sistemática dependen en buena medida la homogeneidad y el éxito de su labor².

Un diccionario es un extracto estandarizado del universo léxico de una lengua en el que se reduce el conjunto abierto de las ocurrencias lingüísticas o variantes de la lengua a un inventario cerrado de invariantes que constituyen lo que se conoce como macroestructura. En ella, cada lema o palabra-entrada ${ }^{3}$ se toma como representante de todas las realizaciones concretas de la voz, ya que se considera que esta forma es la de mayor grado de abstracción, la representación convencional de la unidad léxica. Los lemas encabezan sendos artículos en los que se define la voz y se explican sus principales características. La pluralidad de informaciones que el diccionario aporta sobre cada

1 Este trabajo ha sido realizado gracias a una ayuda de la DGICYT dentro del proyecto "Informatización del Diccionario Crítico Etimológico Castellano e Hispánico de J. Corominas y J. A. Pascual" (Ayuda n. PB92-599).

2 La lexicografía es, pues, una disciplina eminentemente práctica que tiene como finalidad la elaboración de diccionarios y no la discusión teórica acerca de los problemas del léxico; sin embargo, las distintas decisiones que el lexicógrafo toma en el decurso de su trabajo reflejan de forma más o menos consciente la teoría lingüística a la que el autor se adhiere. Luego aunque la lexicografía es una disciplina independiente de la lexicología, lo cierto es que ambas mantienen una estrecha vinculación entre sí y los límites entre una y otra resultan a veces borrosos. Cf. B. QuemaDA (1972).

3 Algunos estudios utilizan también la nomenclatura palabra-clave o voz-guía. 
palabra precisa de una organización dotada de un elevado nivel de formalización, una rígida estructura interna que recibe el nombre de microestructura. En el Diccionario de la Lengua Española de la Real Academia esta información puede englobarse, tal y como propone M. Seco, en dos vertientes: "una, que se refiere a la unidad léxica en cuanto signo, y la otra, que se refiere al contenido de la misma"4. La información sobre el contenido da lugar a la definición. La concerniente a la unidad léxica en cuanto signo abarca elementos de carácter heterogéneo rígidamente normalizados e incluye, tras el lema, la etimología de la voz ${ }^{5}$ y su categoría gramatical; a continuación, ya sea de forma explícita o por omisión, el diccionario proporciona información sobre la localización cronológica6, geográfica y/o social del lema. Por último, y siempre después de la definición, puede aparecer información complementaria habitualmente de tipo gramatical.

El presente estudio analizará un aspecto concreto de la caracterización del lema en cuanto signo en el Diccionario de la Lengua Española de la RAE (vigésima primera edición) $)^{7}$ : el que atañe a las marcas sobre vigencia cronológica que se incluyen de forma explícita en la definición de determinados lemas ${ }^{8}$.

La lexicografía española se configuró desde sus orígenes con una visión marcadamente diacrónica. El Diccionario de Autoridades, primera obra lexicográfica académica, se elaboró tomando como base un corpus de lengua escrita en el que se incorporaron textos de distinta naturaleza de un período comprendido entre el siglo XIII y el XVII, con especial atención a los autores de la segunda mitad del siglo XVI; de este modo, el corpus inicial a partir del que se configuró la planta del primer diccionario académico contenía ya un gran número de voces obsoletas. El Diccionario de la Real Academia en su edición actual admite también entre sus páginas un nutrido número de vocablos arcaicos, lo cual se debe, en buena medida, al hecho de que es el fruto de una larga tradición que parte de la obra dieciochesca y que se ha ido adaptando y modificando a través de las sucesivas ediciones hasta llegar a la actual ${ }^{9}$. No obstante, en el conjunto del DRAE92, el cuerpo de voces con anotación cronológica explícita es reducido, dado que éste es un diccionario de la lengua y no un diccionario histórico. Los diccionarios históricos pretenden compilar de forma exhaustiva el caudal léxico de una lengua a partir

4 Cf. M. SeCO (1987), p. 15.

5 Sobre el tratamiento de la etimología en la lexicografía académica, véase I. AHumada LARA (1989) y M. Alvar EZquerRa (1983), p. 213.

6 Un diccionario de la lengua como es el académico pese a tener una orientación sincrónica incluye también información diacrónica esencialmente de dos tipos: 1) la etimología de las voces que contiene y, en el caso de incluir palabras o construcciones obsoletas, 2) el período histórico en el que éstas estuvieron vigentes.

7 Citamos siempre por Real Academia Española de la Lengua (1992): Diccionario de la lengua española, vigésima primera edición, Madrid, Espasa-Calpe (obra a la que nos referiremos siempre como DRAE92). La abreviatura DRAE84 remite a la vigésima edición del Diccionario académico, de 1984.

8 Lo cual significa que obviaremos otros aspectos también relacionados con la historia de las voces que no se presentan de forma explícita. No analizaremos, por ejemplo, el criterio de ordenación de las diferentes acepciones atendiendo a la cronología de su aparición, ni estudiaremos el acierto en la decisión de separar dos o más palabras homófonas en distintas entradas de acuerdo con su etimología.

9 Cf. M. Alvar EzQuerRa (1976), pp. 155 y ss. 
de una documentación que comprende toda su historia, de tal modo que presentan "la evolución de las palabras a través de los siglos, mediante citas de textos con las correspondientes fechas, indicando las diferentes grafías y las variantes semánticas y morfológicas"10. Frente a este enfoque diacrónico en el estudio de las unidades léxicas, los diccionarios de la lengua se caracterizan por una orientación de corte básicamente sincrónico ${ }^{11}$.

Es cuestión aún debatida si los diccionarios de la lengua deben o no recoger palabras anticuadas. El Diccionario académico ha optado por incluirlas y esta elección puede atender esencialmente a tres motivos. En primer lugar, la lengua es una unidad orgánica en la que pasado y presente se imbrican de tal modo que el presente es incomprensible sin el pasado; así, numerosas locuciones, modismos o frases hechas aún vivas en nuestros días incluyen palabras que ya no se usan ${ }^{12}$. Existe además -en segundo lugar- un gran número de voces, aprendidas esencialmente a través de la lectura, que pertenece al acervo léxico pasivo común de los hablantes cultos; este léxico pasivo modifica la competencia normal de la comunicación porque incluye muchas palabras de épocas pasadas que el hablante actual ya no utiliza pero que todavía comprende $^{13}$. En tercer lugar, puede argüirse también que un diccionario general como el académico podría servir para entender las obras literarias no sólo contemporáneas sino también del pasado; con este fin se recogen en las diferentes ediciones del Diccionario académico abundantes voces documentadas en los autores clásicos que resultan incomprensibles para el lector actual.

El DRAE92 anota las voces o acepciones anticuadas con una marca que informa sobre la época en que dichas palabras estuvieron vigentes en la lengua, bien entendido que la ausencia de dicha marca significa que el término sigue vivo en la actualidad. En efecto, se lee en el epígrafe VII de las ADVERTENCIAS PARA EL USO DE ESTE DICCIONARIO (prólogo del DRAE9Z):

La abreviatura ant., anticuada, indica que la voz o la acepción pertenece exclusivamente al vocabulario de la Edad Media; pero también se califica de anticuada la forma de una palabra, como notomía por anatomía, que, aunque usada hasta el siglo XVII, ha sido desechada en el lenguaje moderno.

La abreviatura desus., desusada, se pone a las voces y acepciones que se usaron en la Edad Moderna, pero que hoy no se emplean ya. En esta edición se usa muchas veces la indicación de desus., o de $p$. us., pues el presente Diccionario, que en sus diferentes ediciones se ha basado siempre en el que la Academia publicó de 1726

10 Cf. G. HAENSCH (1982), p. 117.

11 No obstante, el Diccionario de la Academia, dado que elabora un modelo del léxico del español, reúne un conjunto de palabras que no está en la competencia de ningún hablante, puesto que comprende múltiples variantes dialectales, estilísticas y sociales, así como palabras pertenecientes a distintos estadios de la lengua.

12 Anota R. Menéndez Pidal en "El diccionario que deseamos" (Prólogo a Vox, diccionario general ilustrado, 1945, p. XVII) que, incluso aquel diccionario que atienda exclusivamente a la sincronía, "aunque debe eliminar todo arcaísmo, todavía tiene que incluir aquellas voces y acepciones arcaicas que son necesarias para explicar usos modernos".

13 Cf. Rey-Debove (1973), pp. 82-109. 
esta información no carece de valor, un planteamiento filológico riguroso requeriría una investigación basada en más datos.

\section{La base de datos}

Manejar un corpus de datos extenso y heterogéneo obliga al investigador a organizar de forma ordenada, sistemática y rigurosa la información que maneja; información a la que, además, debe poder acceder con rapidez y facilidad. Actualmente, la informática brinda los medios necesarios para que esto sea posible.

El corpus con el que trabajamos cuenta con casi quinientas voces, para cada una de las cuales ha sido necesario consultar cinco diccionarios distintos: DRAE92, DRAE84, $D H L E$, Aut. y DCECH. Esto suma un total de cerca de dos mil quinientas consultas efectuadas, por lo que ha resultado imprescindible encontrar un modo de ordenar y relacionar toda la información. Con este propósito se ha creado una base de datos en la que se incluye un registro para cada lema en el que se recoge toda la información reunida sobre él. Estos registros contienen campos de diversa índole. En unos se resume la información que cada una de las fuentes consultadas proporciona sobre los lemas estudiados para poder después efectuar un cotejo de los datos que nos permita concluir sobre la veracidad de la notación académica. Mediante un metalenguaje específico creado para este fin, el resultado del estudio se anota en otro tipo de campos que, posteriormente, se han utilizado para un análisis estadístico.

\section{Los límites del método}

Como cualquier método de trabajo, el nuestro tiene también sus límites. El primero y más notorio es que se carece de información sobre un gran número de voces ${ }^{22} \mathrm{y}$ en tal caso por tanto no se puede emitir un juicio sobre la veracidad de su anotación. Lamentablemente, hasta que nuestra lengua no posea un diccionario histórico completo, los estudios de este tipo están condenados a la parcialidad, porque, como afirma Manuel Seco, es arriesgada la pretensión de "fijar el grado de antigüedad de las voces por períodos si no se cuenta con la información suministrada por un diccionario histórico"23.

La inexistencia de un diccionario histórico es, a su vez, causa del segundo de los límites que constriñen nuestro método. En algunas ocasiones no se tiene más fuente de información que la proporcionada por Autoridades, y en estos casos se ha de emitir un juicio tomando como base la fuente lexicográfica dieciochesca, lo cual no es metodológicamente deseable por varios motivos. En primer lugar, porque las documen-

22 Motivo por el cual en la base de datos 192 lemas (un 38,94 \% del total) van anotados con ??. En investigaciones posteriores podría aumentarse el número de fuentes consultadas y revisar los artículos monográficos existentes sobre cada una de las entradas estudiadas. Sin embargo, tampoco esto proporcionaría información suficiente sobre todos los lemas, y sólo se solucionaría en parte el problema.

23 Cf. M. SeCo (1987), p. 187. 
taciones en obras lexicográficas se han de considerar con cierta precaución, pues existe siempre la posibilidad de que hayan tomado como punto de partida para la lematización el caudal léxico de diccionarios anteriores. En segundo lugar, porque, por muy meritorio que sea el Diccionario de Autoridades, no se puede olvidar que se trata de una obra lexicográfica elaborada hace más de doscientos años, cuando la filología moderna aún estaba en sus albores y los académicos -que tendían a estimar modélico el lenguaje de las autoridades- se mostraban reticentes a considerar arcaicos los giros y voces utilizados por los autores clásicos ${ }^{24}$.

Por último, se debe tener en cuenta que "es un gran problema poder saber el nacimiento, vida y muerte de las palabras"25. Todo estudio histórico está condicionado a la existencia de material documental, ya que sólo es posible sacar conclusiones a partir de datos positivos; nunca a partir de datos negativos. La ausencia de documentaciones de una voz en una época determinada no siempre implica que no se usara en aquel período, sino tan solo que no tenemos constancia escrita de ello. Luego cualquier estudio diacrónico se configura inevitablemente como provisional porque posteriores hallazgos pueden invalidar los resultados de investigaciones anteriores ${ }^{26}$. De ahí que si al estudiar los lemas hemos descubierto documentaciones posteriores al período que el DRAE92 propone como época de vigencia de la voz, podemos determinar con seguridad que la información cronológica del diccionario es incorrecta; en cambio, para afirmar sin sombra de dudas que una palabra está bien anotada se tiene que conocer con certeza cuándo cayó en desuso, información que rara vez se puede considerar definitiva. Por ejemplo, tenemos constancia gracias al $D C E C H$ de una documentación de gorgomillera en Juan de la Encina (siglo XVI); de ello se colige, como indica el DRAE92, que la voz no puede ser anticuada porque hay datos positivos que lo desmienten. Ahora bien, para afirmar si la voz es o no desusada, es irrelevante conocer que se sigue registrando en el siglo XVI; necesitaríamos saber o bien cuándo deja de registrarse o, por lo menos, si existen documentaciones del siglo XIX o posteriores, con lo que quedaría descartada la posibilidad de que el lema fuese desusado.

Cabe también considerar la posibilidad de que una voz ya arcaica en el lenguaje oral perviva como forma culta en el uso de autores literarios. Por ejemplo, la última documentación de almadén data -según el DHLE- del año 1615, y aparece en el Rufián dichoso de Cervantes; sin embargo, esta sola documentación no permitiría afirmar que la voz seguía vigente a principios del siglo XVII pues sabemos que Cervantes, como otros muchos autores literarios, podía emplear algunos arcaísmos en sus creaciones ${ }^{27}$.

24 Como afirma Alvar (M. Alvar (1976), p. 44), “los diccionarios antiguos (...) [no deberían utilizarse] como textos informativos de primer orden ya que sus contenidos pueden responder a la conciencia lingüística del autor y no a la situación real".

25 Cf. M. Alvar Ezquerra (1976), p. 136. De igual manera opina I. Ahumada LaRa (1989), p. 65) cuando escribe que, efectivamente, "resulta tarea ardua y dispendiosa, al menos para un buen número de entradas, establecer el grado de vitalidad lingüística en que se encuentran, es decir, establecer si su empleo en la lengua de hoy debe tacharse como arcaísmo o tolerarse como vocablo de escaso uso".

26 Véase a propósito de los problemas e importancia de la datación para la lingüística histórica el artículo de M. Alinel (1991), pp. 107-125.

27 Posteriormente esta voz sólo se documenta en obras lexicográficas. 
RESULTADOS DEL ESTUDIO

\section{La notación académica}

La explicación que proporcionan las ADVERTENCIAS sobre los criterios para marcar las voces obsoletas en el DRAE92 (vid. supra) presenta algunos problemas. Uno de ellos es la dificultad de establecer de forma nítida las fronteras entre los períodos que designan respectivamente las marcas de anticuado, desusado y poco usado. Las voces anticuadas -según la primera acepción del concepto- son las que se usaban únicamente en la Edad Media $^{28}$. Las palabras desusadas se emplearon durante la Edad Moderna ${ }^{29}$, pero no posteriormente. Por último, las poco usadas ${ }^{30}$, aunque irían cayendo paulatinamente en desuso, todavía se emplearían al iniciarse la Edad Contemporánea ${ }^{31}$. Estos períodos históricos de que se sirve la Academia para fijar la vigencia de las voces son borrosos porque no existe unanimidad sobre las fechas que establecen los límites entre unos y otros.

Por otra parte, las tres grandes épocas que se establecen en el DRAE92 para determinar la vigencia de las palabras no coinciden totalmente con las propuestas por el $D H L E$. En efecto, el DRAE92 se sirve de conceptos heredados de la historiografía -Edad Media, Edad Moderna y Edad Contemporánea-, con lo cual el segundo período comprende los siglos XVI, XVII y XVIII. En cambio, el DHLE trabaja con los períodos en que comúnmente se divide la historia de la lengua castellana en el ámbito de los estudios diacrónicos. Esto es: "Uno que comprende hasta 1500; otro desde 1501 hasta 1700 , y otro desde 1701 hasta hoy"32, lapsos de tiempo que se suelen denominar español medieval o antiguo, español clásico y español moderno. La diferencia radica pues en el distinto tratamiento que se da al siglo XVIII ${ }^{33}$.

A su vez, no queda claro cuál es el sentido de moderno en las dos ocasiones en las que aparece en el prólogo. Si debemos entender que Edad Moderna es el período comprendido entre los siglos XVI y XVIII, es de suponer que la lectura correcta de lenguaje moderno es aquella que equipara lenguaje moderno con lenguaje de la Edad Moderna; en cambio, contextualmente parece que se refiere a la lengua contemporánea.

En otro orden de cosas, la marca de anticuada tiene, en el uso que le da la Academia, una segunda acepción según la cual también se considera anticuada la forma, desechada en el lenguaje moderno aunque usada durante el Siglo de Oro, de una voz que ha pervivido en otra variante formal. Por tanto, bajo la abreviatura ant. se engloban dos

28 El DRAE92 s.v. edad entiende por Edad Media el "tiempo transcurrido desde el siglo $V$ de la era vulgar hasta fines del siglo XV" (la cursiva es nuestra).

29 “Tiempo comprendido entre la edad media y la contemporánea", DRAE92 s.v. edad.

30 Son las palabras que G. HaENSCH (1982, p. 163) denomina obsolescentes, "aquellas que el abuelo usa y comprende, que el padre comprende sin usarlas y que el hijo ya no usa ni comprende".

31 Según el mismo DRAE92, "edad histórica más reciente [que] suele entenderse como el tiempo transcurrido desde fines del siglo XVIII o principios del siglo XIX" (la cursiva es nuestra).

32 Diccionario Histórico, "Presentación del primer fascículo", 1960, p VII. Cf. el prólogo del primer volumen aparecido en 1972. 
supuestos: 1) la palabra dejó de usarse antes del Siglo de Oro; 2) el vocablo se siguió usando en el Siglo de Oro y hoy pervive con una forma distinta. En este segundo supuesto, dos términos diferentes, anticuado y desusado, cubren un mismo lapso de tiempo -los siglos XVI y XVII-.

Otro inconveniente que plantea esta nomenclatura es que la distinción entre palabra y forma en que se basa la segunda acepción de anticuado no siempre resulta evidente para el lector poco versado en cuestiones lingüísticas ${ }^{34}$. Además, el hecho de que en la actualidad exista otra forma de la palabra no tiene por qué indicar que esta forma hoy caduca dejara de usarse durante el Siglo de Oro; puede haberse perdido durante la Edad Media. Por ejemplo, absencia, la actual ausencia, aparece en el DRAE92 como anticuada ${ }^{35}$, de lo que se podría deducir tanto que desapareció definitivamente en la Edad Media (primera acepción de anticuado) como que coexistió con la actual ausencia todavía durante el Siglo de Oro y que se perdió en el curso del siglo XVII (segunda acepción de anticuado) ${ }^{36}$. La distinción entre pérdida de palabra y pérdida de variante formal no se aplica sistemáticamente sino sólo en el período de tiempo que abarca los siglos XVI y XVII. Si la forma dejó de usarse, por ejemplo, en el siglo XVIII o XIX y la palabra pervive en la actualidad con una forma distinta, no se indica con ninguna abreviatura específica. Es el caso de albergo, forma antigua de albergue que aún se documenta a fines del siglo $\mathrm{XIX}^{37}$.

${ }^{33}$ A nuestro entender es más conveniente separar el Siglo de Oro del XVIII porque la fundación de la Academia en el año 1713 tuvo grandes repercusiones en la historia de la lengua (Cf. R. LAPESA (1991), pp. 419 y ss.). También es de este parecer M. Alvar EzQuerRa, quien en su Proyecto de Lexicografía Española (p. 47) propone la siguiente división de la historia de la lengua para un hipotético diccionario histórico del español: 1) Desde los orígenes a La Celestina (Época medieval); 2) de La Celestina a la Academia (Siglos de Oro); 3) de la Academia a 1898 ó 1936 (Siglos XVIII-XIX), aunque preferiblemente el año de la famosa generación; 4) el siglo XX.

34 La misma Academia ha ido modificando sus criterios con respecto a esta cuestión a medida que han ido progresando los conocimientos filológicos. Los académicos que trabajaron en la sexta edición del Diccionario (1822) suprimieron muchas entradas de la edición anterior "que sólo eran variantes fonéticas o gráficas de una misma palabra, pues -razonaron correctamente aquellos académicos- los diversos estados de pronunciación y ortografía que padece una voz (...) no deben mirarse como palabras diversas" (cf. M. AlvaR EzQUeRRA (1983), p. 206). Resulta interesante constatar que el DHLE trata dentro de un solo artículo todas las variantes ortográficas y fonéticas de una misma voz; con ello se quiere evitar la innecesaria dispersión de lo que se considera una misma palabra.

35 La existencia de esta forma en la Edad Media está asegurada por la documentación en La Gran Conquista de Ultramar (h. 1300) que proporciona el DCECH. El problema se reduce, pues, a establecer la caída en desuso de la misma.

${ }^{36}$ El grupo consonántico $\mathrm{b}(\mathrm{C}) \mathrm{C}$ alternó durante toda la Edad Media la pérdida con la conservación del elemento en posición implosiva. Ya en el siglo XV apareció otra variante en la que se sustituía $b$ por u. Cfr. G. ClaveriA (1991), p. 131.

37 Cf. DHLE, s. v. 


\section{La caracterización diacrónica de los lemas en el DRAE92}

\subsection{Tipología de las marcas cronológicas: diversidad de fenómenos}

Los problemas en la caracterización diacrónica de los lemas no derivan únicamente de la dificultad que conlleva conocer la época en que una palabra dejó de usarse e intentar clasificarla de acuerdo con una nomenclatura rigurosa, sino que nacen también de la variedad de fenómenos lingüísticos de índole diversa que se esconden bajo una marca de vigencia cronológica.

\subsubsection{Aspectos lingüísticos}

a) Cambios en la forma

Pueden considerarse cambios en la forma aquellos que tienen relación con la pérdida de una de las variantes que durante un período determinado coexistieron para una misma palabra sin que hubiese ninguna diferencia de significado entre ellas, por lo que la pervivencia de una en detrimento de la(s) otra(s) es el resultado de un proceso de selección de variantes que ha tenido lugar en el devenir de la historia de la lengua.

\section{Variantes ortográficas y fonético-fonológicas}

Algunas palabras han presentado a lo largo de su historia alternancias gráficas y/o fonéticas, una de las cuales ha acabado por imponerse en detrimento de las demás. Cuando las formas alternantes están ampliamente documentadas, el Diccionario deja constancia de ello ${ }^{38}$. Un buen número de los términos antiguos que se recogen en el DRAE92 no son de hecho más que puras alternancias ortográficas y fonético-fonológicas de una misma voz.

Durante la Edad Media y todavía en el español clásico, era corriente que algunas voces sufriesen alternancias vocálicas semejantes a las que encontramos en abromar / abrumar ${ }^{39}$, adahala / adehala, amnestía / amnistía, apercebir / apercibir, bretánico / británico, creatura / criatura, amochiguar / amuchiguar, asconder / esconder, eglesia / iglesia, emprenta / imprenta, etc. Las palabras que tenían grupos cultos también presentaron vacilaciones en su pronunciación que se manifestaron en variantes gráficas como absencia / ausencia, absentarse / ausentarse, absente / ausente, absconder / asconder (/ esconder); dotor / doctor, dotrina / doctrina; egiciano / egipciano o acetar / aceptar, batisterio / baptisterio.

La forma de muchas unidades léxicas que utilizamos actualmente coexistió en la lengua antigua con otra forma que presentaba una aféresis o una prótesis -mayoritariamente de vocales pero también de algunas consonantes-40; este es el caso de abita / bita, acerca / cerca2, adamante / diamente, alacayo / lacayo, amaniatar / maniatar,

38 En estos casos, la definición del lema antiguo consiste en una remisión a la forma actual.

39 Todos los ejemplos -también las definiciones- que a continuación se comentan pertenecen al corpus que venimos manejando y, por tanto, todos se han extraído del DRAE92. Cualquier ejemplo en cursiva sin otra referencia remite a la entrada correspondiente de este diccionario.

40 Estas alternancias pueden ser meramente fonéticas pero en ocasiones tienen una explicación morfológica. 
apaniaguado / paniaguado, aparamento / paramento; cumular / acumular, etc. Cabe también la posibilidad de que la variante vigente en nuestros días haya surgido por una una síncopa de vocal intertónica -adáraga / adarga, adárame / adarme-, por una reordenación de fonemas -apertar / apretar- o por una prótesis epentética-aproar 1 / aprodar-.

Asimismo, las voces obsoletas a las que el DRAE92 da cabida, pueden dejar constancia de cambios que han tenido lugar en la evolución histórica del castellano y que se han consolidado como, por ejemplo, la aspiración de $<\mathrm{h}>$ cuando provenía de una Fetimológica latina; véanse los pares ahirmar / afirmar, fijo / hijo, fazaña / hazaña, farina / harina. Pueden también plasmar procesos que existieron pero que no llegaron a triunfar. Es el caso de desenhadar vs. desenfadar, palabra derivada de enfadar, verbo que -según explica el $D C E C H^{41}$ - es un préstamo del gallego-portugués enfadar-se que se documentó con la forma enhadarse ${ }^{42}$ lo cual parece un intento de castellanización fonética del vocablo portugués. La forma prefijada correspondiente desenhadarse se halla documentada en la Confission del Amante (año 1400) y en Nebrija. Finalmente, algunas variantes caducas pueden incluso "fosilizar" procesos de fonética sintáctica que en su día se produjeron; v. g. doy (= de hoy) y empós (= en pos).

\section{Variantes morfológicas}

Otras palabras, en cambio, han presentado en el devenir de los tiempos vacilaciones entre distintas soluciones morfológicas de las cuales sólo una ha pervivido. Muchas de ellas serían aún formas posibles en el sistema del español moderno pero la propia evolución del idioma ha acabado desechándolas. Algunas alternancias se registran en los prefijos: adhortar / exhortar, amarañar / enmarañar, antedecir / predecir, anteferir / preferir, antehistórico / prehistórico, anteocupar / preocupar, desenquietar / inquietar, desreverencia / irreverencia, desplayar / explayar, emprisionar / aprisionar, encuñar / acuñar; otras, en cambio, en los sufijos: ablandura / ablandamiento, absolvimiento / absolución, adestranza / adiestramiento, ahincamiento / ahincanza / ahínco, amarilleza / amarillor / amarillura / amarillez, amistanza / amistad, aprobanza / aprobación, arrastradura / arrastramiento, convertimiento / conversión, escureza / escuridad, esforzamiento / esfuerzo, esmeramiento / esmero, fortitud / fortaleza; arbitradero / arbitrable, fazañero / fazañoso; ablandecer / ablandar, adherecer / adherir, agravecer / agravar, amodorrecer / amodorrar, despolvorizar / despolvorear, escurar2 / escurecer, etc. ${ }^{43}$

b) Modificaciones en el componente léxico

La desaparición de una palabra se puede deber al hecho de que la realidad extralingüística que el vocablo designaba se haya perdido o bien a que haya tenido lugar una substitución en la denominación de dicha realidad. Sirva para ilustrar el primer caso la

41 Cf. DCECH, s. v. enfadar.

42 En Nebrija y Hernán Núñez. DCECH, s. v.

43 Sobre el comportamiento, documentación y alternancia de sufijos en verbos derivados y sustantivos verbales, véase J. PENA (1980). 
voz acroe (sinónimo de acroy) 44 , 'gentilhombre de la casa de Borgoña, que acompañaba al soberano en ciertos actos públicos y le seguía a la guerra' 45 . En el momento en que este cargo político se suprimió, la voz hubo de convertirse en un anacronismo, por lo que pronto caería en desuso. Son ejemplos similares manuela 'en Madrid, coche de alquiler, abierto y tirado por un caballo' o behetría 'antiguamente, población cuyos vecinos, como dueños absolutos de ella, podían recibir por señor a quien quisiesen'46.

En la substitución de denominaciones el concepto que designa la voz pervive bajo un nuevo significante. Por ejemplo, acertero, 'objeto sobre el que se dispara un arma de fuego', recibe actualmente el nombre de blanco; un antecuarto se conoce ahora como recibidor, un escurra es un truhán; y la mayoría ignora en nuestros días que un desentido era lo que ahora denominaríamos un loco. El significante que haya venido a sustituir la denominación previa de un concepto ya existente puede ser también un sintagma, como en agreza, término para el cual hoy usaríamos la expresión sabor acre o colorir para el que ahora utilizamos el sintagma verbal dar color o el verbo colorear.

Sucede a menudo que una voz patrimonial o derivada es sustituida por un cultismo. Este es el caso de esponsales --tomado del latín sponsalis- que ha triunfado frente al antiguo y patrimonial desposajas. ${ }^{47}$ Esleer y su variante esleír parecen ser -según explica el $D C E C H$ - adaptación semipopular del vocablo latino eligere que posteriormente por influjo culto acabó siendo sustituido por la forma culta elegir ${ }^{48}$. El caso de esculpidor es algo distinto. Esculpidor fue una palabra creada por derivación, con el sufijo castellano -dor, a partir de esculpir, un latinismo documentado ya en A. Palencia; con posterioridad ${ }^{49}$ esta voz fue relegada por escultor, que se tomó directamente del latín sculptor, -oris.

Es relativamente frecuente que alguna de las acepciones de una palabra quede anticuada. Esto es lo que sucede con abstener, que en nuestros días ya no conserva el significado de 'contener o refrenar; apartar' que fue habitual hasta el siglo XVII, o con adicción, que ha perdido la acepción 'asignación, entrega, adhesión'. En algunos casos, como el de convenencia, se ha perdido una acepción, la de 'ajuste, convenio', y ha pervivido otra, la de 'correlación y conformidad entre dos cosas', pero bajo la variante conveniencia.

Si el significante perdura puede producirse una ampliación o restricción del contenido, debido a que alguno de los componentes identificables por separado que configuraban el significado total de la palabra ha desaparecido. Así, adjetivar, todavía en el Siglo de Oro 'concordar una cosa con otra', se convierte en español moderno en 'aplicar adjetivos'. Por el contrario, la extensión del significado de una palabra puede

44 En el DRAE92 sólo aparece anotada como desusada acroe, pero no la variante acroy. Sin embargo, el $D H L E$ documenta ambas formas por última vez en el siglo XVII. Es además significativo que el artículo que el DRAE92 dedica a la voz acroy use en la definición exclusivamente verbos en pretérito, aunque no haga mención explícita de que sea una voz ya desaparecida.

45 DRAE92, s. v. acroy.

46 Acroy, behetría y manuela no llevan en el DRAE92 niguna marca de uso.

47 Explica el $D C E C H$ s.v. esponsales que del plural neutro SPONSALIA derivó la forma leonesa esposayas -documentada en el Fuero Juzgo (1291) - de la que existió la variante castellana desposajas.

48 Existió incluso una forma eligir que se documenta en Nebrija.

49 La primera documentación que recoge el $D C E C H$ es del año 1600. 
ampliarse. El plural parientes equivalía en español medieval a 'los padres'50; posteriormente, la voz cobra un sentido más general y pasa a significar, respecto de una persona, 'cada uno de los ascendientes, descendientes y colaterales de su misma familia, ya sea por consanguinidad o por afinidad'.

\subsubsection{Variantes diatópicas y diastráticas}

Algunas de las voces que el DRAE92 recoge y tilda de anticuadas o desusadas han tenido existencia sólo como dialectalismo. Éste es el caso de estema1 y estemar, que, tal y como recoge el DRAE92, únicamente se han documentado como pertenecientes al aragonés antiguo; según el $D C E C H$ también sería voz aragonesa antigua albarráneo, aunque no lleva ninguna marca diatópica en el DRAE92. Son casos análogos adieso, voz anticuada que según el $D C E C H$ sólo existió en aragonés y leonés antiguos, o despullar, que, de nuevo según el $D C E C H$, desde los orígenes fue variante dialectal leonesa.

Pueden documentarse también variantes cuya pervivencia como dialectalismo va más allá de la pérdida de la voz en el resto del dominio lingüístico del castellano. Empujada 'empujón', correctamente anotada como anticuada por el DRAE92, se usa actualmente en "Argentina, Guatemala, Uruguay y Venezuela" ${ }^{2}$. Otras voces, a su vez, aparecen con marca diacrónica pero carecen de marca diatópica en el DRAE92, aunque según el $D C E C H$ o el $D H L E$ perviven en alguna zona del dominio lingüístico hispánico. Por ejemplo, alacayo 'lacayo' se mantiene en el castellano del País Valenciano y en Mallorca; absolvimiento pervive hoy en Argentina; agro2 se registra actualmente como variante dialectal en América y algunas hablas peninsulares; ahogar2 se mantiene aún vigente en Andalucía y Bogotá52.

En ocasiones, una palabra que se documenta en la lengua antigua como propia de una zona dialectal se conserva en la actualidad también como voz dialectal pero con una extensión territorial distinta. V. g. bribia, según el $D C E C H$, sigue viva entre los sefardíes de Marruecos a pesar de que se ha perdido en la zona que ocupó el antiguo dialecto leonés, al que perteneció originariamente.

Entre los lemas obsoletos que recoge el DRAE92 se han documentado ejemplos en los que la voz ha pervivido hasta nuestros días como variante diastrática. Éste es el caso de las anticuadas agrear 'agriar' y dotor 'doctor' que modernamente se encuentran como vulgarismo en algunas regiones según el $D H L E$ y el $D C E C H$ respectivamente. La Academia proporciona en ambos casos una correcta anotación diacrónica pero omite la información que atañe al nivel de uso ${ }^{53}$.

51 DRAE92, s. v. En el DCECH sólo aparece como dialectal venezolana.

52 La información dialectal sobre absolvimiento y agro2 la proporciona el $D H L E$; para alacayo y ahogar2, la fuente utilizada ha sido el $D C E C H$.

53 En nuestro corpus aparecen marcadas como vulgares por la Academia apertar, cevil, empolla y emprestar, escuras, escurecer pero no poseemos datos suficientes para verificar esta información. 


\subsection{La anotación académica de los lemas del corpus}

Del estudio de las marcas que acompañan a las voces anticuadas del DRAE92 se desprende una serie de conclusiones que resumimos a continuación. En primer lugar, se ha constatado que no pocos lemas de los estudiados presentan una información cronológica errónea según los datos obtenidos a partir de las fuentes lexicográficas consultadas ${ }^{54}$. En la mayoría de los casos sucede que una palabra está documentada en una época posterior a la que engloba el término con que aparece anotada. El DRAE92 recoge, por ejemplo, la voz ahorría como anticuada. De ser esto cierto, la última documentación que existiera debería ser del siglo XV o anterior. Sin embargo, consultadas las fuentes de información histórica, se averigua que la voz se documenta todavía en una obra de A. Cabrera del año $1601^{55}$, y que tiene su última documentación conocida en $1623^{56}$; de ello se colige que la voz es desusada. Puede suceder, incluso, que la primera documentación que se tiene de la palabra sea posterior al lapso de tiempo que define la nota que acompaña al lema. V.g. adiamiento, anotada por la Academia como anticuada, está documentada por primera vez en el año $1685^{57}$. De esta documentación tan tardía se deduce que el vocablo quizá sea desusado, o quizá poco usado, pero nunca anticuado.

Es posible, también, que la voz se registre en la actualidad y esté marcada como no vigente. Es el caso de comportar, que en su acepción 'llevar juntamente con otro alguna cosa' está clasificada en el DRAE92 como anticuada; no obstante, el DCECH afirma que, aunque siempre ha tenido un uso restringido, ha seguido empleándose hasta nuestros días. Por lo tanto, esta voz en rigor no debería tener notación cronológica sino alguna indicación diastrática.

Algunas veces, el error en la anotación se halla en una sola acepción de la palabra, pero están correctamente anotadas las demás. Absolvimiento, en el significado más amplio de 'absolución', 'pena' es, según la información que proporciona el $D H L E^{58}$, desusada -hecho que entra en contradicción con la marca ant. que tiene en el DRAE92-, pero en la acepción más restringida de 'absolución sacramental' se ha documentado sólo en Alfonso $\mathrm{X}^{59}$, con lo que se confirmaría aquí la clasificación académica.

54 No obstante, hay que tener en cuenta que la información que proporcionan estas fuentes no es siempre es coincidente. Por ejemplo, la palabra alfayate 'sastre' viene marcada como ant. en el $D C E C H$, donde se explica: "En la lucha con sastre, que ya aparece en 1302, acabó por triunfar éste en castellano". Sin embargo, el DHLE no la anota como no vigente en la actualidad, pese a que sólo la documenta cuatro veces desde el siglo XVIII.

55 Documentación que aporta el $D C E C H$.

56 Cf. $D H L E$, s. v.

57 El DCECH no da constancia de la voz adiamiento, aunque sí estudia adiar (documentada en el Fuero de Navarra, siglo XV) y adiado (documentada en 1607). El DHLE documenta adiamiento por vez primera en una ejecución de nobleza del año 1685.

58 La primera vez que el $D H L E$ recoge esta acepción es en la segunda edición del primer tomo de Autoridades (letras A-B) del año 1770. Aunque la única documentación que poseamos pertenezca a una obra lexicográfica, creemos que la autoridad de la Academia cuando acepta este testimonio como válido en la elaboración del $D H L E$ nos permite clasificar esta acepción como desusada.

59 En Las Siete Partidas, DHLE, s. v. 
Por último, existe un reducido número de voces para las cuales el período en que dejaron de usarse según la información del DRAE92 es posterior a la última documentación que aporta el $D H L E$ y, por ende, a la fecha en que presumiblemente cayeron en desuso. Así sucede en adarvar1, que aparece como poco usado en el DRAE92, pero cuya última documentación data del año 1631, según recoge el $D H L E^{60}$; luego la voz sería desusada, lo cual se ve avalado por el hecho de que en Autoridades ya se anota el lema como poco usado.

Debe tenerse en cuenta, no obstante, que nosotros sólo hemos estudiado lemas arcaicos en los que hay una marca cronológica explícita, pero existen en el DRAE92 múltiples voces antiguas que carecen de marca diacrónica. Ocurre a veces que la redacción de la definición de alguno de estos lemas pone de manifiesto el carácter arcaico del vocablo definido con el uso de expresiones del tipo decíase o usábase, o utilizando tan solo verbos en tiempos pretéritos ${ }^{61}$. La quinta acepción de la voz mecánico, que aducimos a modo de ejemplo, no está anotada como obsoleta mediante ninguna de las convenciones que en el DRAE92 se emplean para ello, pero se define en los siguientes términos:

Decíase de los oficios u obras que exigen más habilidad manual que intelectual62.

La caracterización diacrónica de los lemas puede presentar, además de los expuestos, problemas de otra índole. En alguno de los ejemplos de nuestro corpus, el DRAE92 omite información dialectal referente al lema estrechamente relacionada con su historia, que se refiere, las más de las veces, a la pervivencia del vocablo como variante regional más allá de la pérdida de la voz en la lengua estándar ${ }^{63}$. Así ocurre en colpe -voz anticuada correctamente anotada por la Academia-, que el $D C E C H$ documenta hoy en día como variante del vascuence, o en desque, combinación que estuvo en curso hasta el siglo XVI y que se ha mantenido como regionalismo en Asturias ${ }^{64}$.

Existe por último la posibilidad de que se tenga constancia de la forma sólo como variante dialectal, lo cual debería quedar explícito en la entrada. Ejemplo de ello es des-

60 El DHLE lo documenta en los Refranes de Correas.

61 Algunos ejemplos de ello son augur, áureo (sexta acepción), autor (cuarta acepción), aventurero (acepciones cuarta y quinta), azafata (primera acepción), azote (octava acepción), azulete (primera acepción), onfacomeli, oxizacre. Hay otros lemas sin anotación cronológica cuya definición contiene el adverbio antiguamente con el cual se indica que la voz, la acepción o la realidad a la que ésta alude ya no existen; ejemplos de ello son, entre otros, abanderado (quinta acepción), abridor (sexta acepción), acañaverear, acémila (segunda acepción), cerate, cetra, ciclada, congregación (segunda acepción), crespín, manuela (vid. supra).

62 La cursiva es nuestra. Vid. supra también la definición de la voz acroe. Otros lemas sin marca de uso diacrónico en los que la definición o alguna de sus acepciones aparece encabezada por decíase son aguijatorio, aguijeño, articulado (cuarta acepción), cimarrón, criminalista (tercera acepción), cómico (segunda acepción), nervino, ordinario (séptima acepción).

63 Evidentemente, la pervivencia de la palabra con carácter dialectal puede afectar sólo a una acepción.

64 Cf. DCECH, s. v. Ya Juan de Valdés la censura con el uso de 'cuando', aunque todavía la siguen empleando en verso autores del siglo XIX como convención del lenguaje literario. 
pullar ${ }^{65}$, que fue de uso común sólo en leonés antiguo, y que el DRAE92 anota como dialectal anticuada sin especificar la zona en que se empleó; o casos como el de bribia, ya analizado, que antiguamente se documenta sólo como variante leonesa ${ }^{66}$ pero que en la actualidad es la forma propia de los sefardíes de Marruecos, y que el DRAE92 sólo anota como anticuada.

Mención aparte merece un tercer tipo de problemas que afectan al principio mismo de pretender establecer divisiones nítidas en la historia de la lengua, que, como proceso histórico que es, escapa a las divisiones arbitrarias que se establecen para su estudio. Cuando se intentan clasificar las palabras no vigentes en castellano atendiendo a una segmentación de la historia de la lengua en compartimientos estancos, se hallan voces cuya adscripción a uno u otro período resulta difícil porque dejaron de usarse en un lapso de tiempo que está a caballo entre dos de los períodos que se usan para clasificarlas; son lemas que se pierden en épocas que podríamos denominar de transición ${ }^{67}$. V. g. cras, adverbio temporal que, según J. Corominas y J. A. Pascual, se sentía ya como caduco hacia 1500, pese a que no faltan ejemplos de él en los siglos XVI y XVII, aunque ya siempre en frases proverbiales y anécdotas antiguas. La aplicación rigurosa de los criterios de anotación es en estos casos necesaria y deseable, pero falsea inevitablemente la realidad porque simplifica en exceso unos hechos harto complejos.

\section{Recuento y estadística}

La base de datos que hemos utilizado para procesar la información permite efectuar recuentos automáticos que pueden servir para realizar cálculos estadísticos que, aunque rudimentarios, describen de forma general el problema analizado. Un estudio que se limite a tomar unas pocas voces y extraiga a partir de ellas conclusiones con pretensiones de generalidad peca, indefectiblemente, de parcialidad; por el contrario, cuanto mayor sea el número de voces tratado, menor es el margen de error que existe en la extrapolación. Nuestro corpus consta de 493 lemas que constituyen el $5 \%$ de las voces con marca cronológica recogidas en el DRAE92. Concluido el estudio de cada

65 El DCECH, s. v. despojar, afirma que "la variante antigua despullar que cita la Academia es dialectal, al parecer leonesa, y se halla en una versión doscentista de la Biblia".

66 El DCECH, s. v., después de afirmar que es pronunciación leonesa, documenta esta voz bribia en Santillana, Gómez Manrique y el Cancionero de Baena. También la documenta en manuscritos del siglo XVI y en el Guzmán.

67 En nuestra base de datos, marcábamos estos casos con un asterisco. Concretamente, se han marcado de este modo (*) 28 registros, que suponen un 9,3\% del total (calculado sobre 301 voces, aquellas de las que tenemos suficiente información como para emitir un juicio) cuando la documentación que teníamos atestiguaba que el lema se había perdido quince años antes o después de los límites temporales fijądos para determinar el período en que la voz desapareció. Con ello hemos pretendido dejar constancia de que existen unos lapsos de tiempo entre los establecidos para clasificar la vigencia de los lemas -anticuado, desusado, poco usado- que en rigor no pertenecen a ninguno de ellos sino que constituyen ellos mismos un período de cambio; las fronteras son, en estos casos, poco claras y por consiguiente se dificulta enormente la decisión del lexicógrafo. 
uno de ellos, se carecía de información suficiente para juzgar la validez de la información diacrónica en 192 lemas -esto es, un 38,94 \% del total-, lo cual reduce el corpus original a 301 lemas, número que servirá de base para calcular los porcentajes que inmediatamente presentamos.

El primer recuento efectuado hace referencia a la correspondencia entre la información que aporta la anotación del DRAE92 y la que se deduce de las fuentes lexicográficas que se han consultado; resumimos el resultado en la siguiente tabla:

\begin{tabular}{|lcr|}
\hline Anotación & $n^{\circ}$ elementos (301) & $\%$ \\
\hline correspondencia & 142 & 47,18 \\
posible correspondencia68 & 49 & 16,28 \\
Total & 191 & 63,45 \\
no correspondencia & 105 & 34,88 \\
posible no correspondencia69 & 5 & 1,66 \\
Total & 110 & 36,54 \\
\hline
\end{tabular}

Los datos de la tabla precedente se obtienen al aplicar rigurosamente el criterio de clasificación que la Academia propone en su prólogo. No obstante, y como ya hemos explicado, este criterio encierra ciertas ambigüedades, debidas, sobre todo, a la segunda acepción de anticuado. Se ha creído necesario, para calibrar la importancia de este problema, efectuar un cómputo de las voces afectadas por dicha acepción, cuyo número asciende a 77 , lo cual supone un $25,58 \%{ }^{70}$.

Son 27 (9,34\%) las palabras a las que, a partir de nuestros datos, les falta información dialectal de algún tipo. Sin embargo, hay que tener en cuenta que no se ha sido exhaustivo en este aspecto y que, por tanto, el dato tiene una validez relativa; no

68 No podemos sacar conclusiones taxativas sobre estos 49 casos, pero los datos obtenidos en el $D H L E$, el DCECH y Autoridades parecen confirmar la información cronológica del DRAE92. V.g.: almadén es, según el DRAE92, palabra desusada. La última documentación que da el DHLE data del siglo XVII (1615, Cervantes); luego, es, como bien indica la Academia, desusada. Sin embargo, además de en Autoridades está también documentada en varios diccionarios posteriores. Esto podría hacer pensar que es poco usada, aunque las documentaciones en las obras lexicográficas no son siempre fiables, dado que existe la posibilidad de que tomen como base de la lematización algún diccionario anterior.

69 Carecemos de información explícita sobre estos lemas pero los datos que poseemos podría parecer que desmienten las marcas del DRAE92. V.g.: la voz desquito está recogida en el DRAE92 como anticuada. No hay información sobre desquito como participio de desquitar, pero sí de quito como participio de quitar (primitivo de desquitar). El hecho de que este último no se documente hasta el siglo XVI podría hacer suponer para desquito una primera documentación por los mismos años. De ser esto cierto, la voz no sería anticuada sino desusada.

70 De eliminarse el segundo significado de anticuado, todos ellos deberían estar anotados como desusados. 
obstante, sería necesario efectuar un análisis sobre la información dialectal que proporciona el DRAE92 análogo al que nosotros hemos llevado a cabo para la información diacrónica, y para el cual sería necesario consultar un material distinto a las fuentes que hemos utilizado.

Ofrecemos, finalmente, una tabla que recoge los cambios -en su mayor parte mejoras- que la edición del DRAE92 presenta respecto a la inmediatamente anterior (DRAE84). Estos cambios pueden afectar bien a la definición del lema, bien a la marca de carácter diacrónico que lo acompaña:

\begin{tabular}{|lrr|}
\hline Cambios 1992 & $n^{\circ}$ elementos & $\%$ \\
\hline Cambios en la definición del lema & 9 (sobre 98) & 9,18 \\
Cambios en las marcas diacrónicas & 90 (sobre 98) & 91,84 \\
Total & 98 (sobre 493) & 19,88 \\
\hline
\end{tabular}

En los 90 casos en que ha habido cambios en la anotación de vigencia cronológica del lema, los resultados han sido los siguientes:

\begin{tabular}{|lcc|}
\hline Tipo de cambio & $n^{\circ}$ elementos & $\%$ \\
\hline $\begin{array}{l}\text { se añade una marca a un lema } \\
\text { que no la tenía }\end{array}$ & 71 (sobre 90) & 78,89 \\
$\begin{array}{l}\text { la marca se corresponde con la } \\
\text { información de las fuentes históricas } \\
\text { la marca no se corresponde con la información }\end{array}$ & 30 (sobre 71) & 42,25 \\
$\begin{array}{l}\text { de las fuentes históricas } \\
\text { no podemos pronunciarnos }\end{array}$ & 11 (sobre 71) & 15,49 \\
$\begin{array}{l}\text { se cambia la marca de un lema que ya estaba } \\
\text { anotado }\end{array}$ & 30 (sobre 71) & 42,25 \\
$\begin{array}{l}\text { la marca se corresponde con la información } \\
\text { de las fuentes históricas } \\
\text { la marca no se corresponde con la información }\end{array}$ & 19 (sobre 90) & 21,11 \\
$\begin{array}{l}\text { de las fuentes históricas } \\
\text { no podemos pronunciarnos }\end{array}$ & 2 (sobre 19) & 11 (sobre 19) \\
\hline
\end{tabular}

Insistimos en que los resultados de estas tablas se basan en los datos que aportan las fuentes lexicográficas que hemos consultado. No obstante, como ya se ha explicado, dichas fuentes no permiten emitir un juicio definitivo acerca de todas las voces de nuestro corpus; el DRAE92 añade o modifica las marcas de información cronológica del DRAE84 en 90 casos, para 36 de los cuales carecemos de información suficiente. De los 54 cambios restantes, 41 (el 75,93\%) son mejoras respecto a la edición anterior. 


\section{CONCLUSIONES}

El objetivo de nuestra labor ha sido el de analizar la información diacrónica que el DRAE92 aporta sobre las palabras actualmente no vigentes mediante el uso de un metalenguaje específico que informa al lector sobre la época en que dichas voces cayeron en desuso. Las conclusiones a las que se ha llegado en este estudio pueden resumirse en tres consideraciones finales:

1) Un análisis sobre las marcas diacrónicas en un diccionario de la lengua evidencia que tras una nota cronológica subyacen fenómenos lingüísticos diversos y a menuso complejos, puesto que un cambio en cualquier nivel de la lengua puede tener repercusiones en el léxico, tal y como se refleja en las palabras estudiadas. Anticuado, desusado o poco usado son marcas que pueden describir fenómenos tan diversos como la desaparición de una variante ortográfico-fonética o morfológica arcaica, la pérdida de una acepción o el olvido de un término que cayó en desuso al desaparecer el concepto que designaba dicha palabra o al ser substuido por otra forma. Asimismo, estos cambios no siempre afectan de forma uniforme ni a todo el territorio lingüístico ni a todos los niveles de uso.

2) En el epígrafe VII de las AdVERTENCIAS PARA EL USO DE ESTE DICCIONARIO (pág. XXII) se explica cuáles son y qué significan las abreviaturas que orientan a quien consulta el diccionario sobre la vigencia de los lemas a través de los siglos. Según lo allí expuesto, la pretensión académica es la de fijar el grado de antigüedad de las voces por períodos, para lo cual se establece una escala cronológica en base a edades históricas a las que corresponden sendas abreviaturas. Sin embargo, estos criterios de marcación resultan, en la práctica, algo confusos por varios motivos:

a) No se define la abreviatura $p$. us.

b) La marca anticuado hace referencia a dos realidades distintas, y en su segunda acepción cubre un período cronológico que se superpone parcialmente con el que abarca el concepto de voz desusada.

c) Los conceptos anticuado, desusado y poco usado se corresponden con unos períodos históricos -Edad Media, Edad Moderna y Edad Contemporánea- sobre cuyos límites no existe un criterio unánime entre los historiadores.

Por lo expuesto anteriormente, y con la convicción profunda de que "la lexicografía ha de actuar con arreglo a una metodología lo más rigurosa posible"71, parecería oportuno, primero, limitar el concepto de palabra anticuada a su actual primera acepción según la cual serían voces o acepciones anticuadas las que pertenecieron exclusivamente al vocabulario de la Edad Media; segundo, ofrecer una posible definición de voz poco usada, $\mathrm{y}$, tercero, proponer unos límites claros -aunque siempre serán hasta cierto punto arbitrarios- para los términos que establecen la vigencia cronológica de las palabras. 
3) Los criterios que los académicos usan para anotar hasta cuándo una palabra se mantuvo vigente en nuestra lengua se concretan, pues, en una clasificación que, "aparte de confusa (¿por qué ese doble sentido de anticuada?; ¿qué se entiende por moderno las dos veces que se usa ese término?), tiene el inconveniente de que en la práctica se realiza de una manera defectuosa"72. Aunque la mayoría de los lemas están bien anotados, un $35 \%$ de las voces de nuestro corpus tiene una caracterización cronológica que no se corresponde con la obtenida en las fuentes lexicográficas consultadas, sea porque existen documentaciones posteriores, sea porque, al contrario, el $D H L E$ avanza la última documentación. Hay que tener en cuenta, no obstante, que nosotros sólo hemos revisado lemas con indicaciones cronológicas explícitas, pero hay otras entradas que carecen de esta indicación y que, en cambio, debieran llevarla. Por ejemplo, "términos como albardanería y ablandahígos, cuyos últimos testimonios de uso, según el Diccionario Histórico (...), se quedan respectivamente en los años 1537 y 1611 , aparecen en el Diccionario común como vivos y normales"73 en la actualidad.

Cierto es, sin embargo, que la Academia mejora su diccionario en cada edición. Si se compara el DRAE92 con el DRAE84 se constata que en la última edición del Diccionario la Academia ha añadido nota cronológica en palabras que tenían indicación cero de vigencia y ha corregido algunos errores manifiestos que aparecían en la anterior edición, de modo que, en nuestro corpus, el $75 \%$ de los cambios introducidos en la última edición subsanan errores de la anterior. Es de esperar que futuras ediciones continúen mejorando las precedentes y que consigan una precisión mayor en el tema que nos atañe. Como afirma M. Alvar, "el diccionario académico es excelente por las voces del pasado que atesora"74, pero son aún "muchas las deficiencias por corregir y los errores por subsanar en el futuro: sólo así seguirá vivo el diccionario, desempeñando la función que le corresponde. El académico no es perfecto, y dista mucho de serlo, pero tampoco es deleznable. Es una piedra preciosa en bruto, si el usuario sabe tallarla conseguirá una maravilla, pero si sus manos son torpes la perderá"75.

\section{BIBLIOGRAFÍA}

Ahumada Lara, I. (1989): Aspectos de lexicografía teórica. Aplicaciones al Diccionario de la Real Academia Española, Granada, Universidad de Granada.

Alarcos, E. (1983): “Consideraciones sobre la formación léxica”, en Serta Philologica F. Lázaro, Madrid, Cátedra.

Alinel, M. (1991): “The Problem of Dating in Historical Linguistics", Folia Linguistica Historica, 12/1-2, pp. 107-125.

. SECO (1987), p. 137

73 Cf. M. SeCO (1987), pp. 55-56.

74 Cf. M. Alvar Ezquerra (1993), p. 248.

75 Ibid. 
Alvar EzquerRa, M. (1993): “Ante la vigésima edición del DRAE", en Lexicografía descriptiva, Barcelona, Biblograf, pp. 241-248.

Alvar EzquerRa, M. (1991): “Atlas lingüísticos y diccionarios" en Estudios de geografía lingüística, Madrid, Paraninfo, pp. 49-115.

Alvar EzQuerRa, M. (1983): "Los prólogos del Diccionario académico. Nomenclatura específica y microestructura", Revista de Filología Española, 63, pp. 205-222.

Alvar EzQuerRa, M. (1976): Proyecto de lexicografía española, Barcelona, Planeta.

CASARES, J. (1950): Introducción a la lexicografía moderna, Madrid, RFE, Anejo 62. (Reimpresión 1969).

Clavería, G. (1991): El latinismo en español, Bellaterra, Universidad Autónoma de Barcelona.

Corominas, J., y J. A. Pascual (1980-1991): Diccionario Crítico-Etimológico Castellano e Hispánico, 6 vols., Madrid, Gredos.

DuBols, J. \& C. (1971): Introduction à la lexicographie: le dictionnaire, París, Larousse.

HaEnsCH, G. (1982): “Tipología de las obras lexicográficas”, en G. Haensch et al., La lexicografía. De la lingüística teórica a la lingüística práctica, Madrid, Gredos, pp. 95-187.

Hartmann, R. R. K. (1983): “On theory and practice”, en R. R. K. Hartmann et al., Lexicography: principles and practice, London, Academic Press, pp. 3-11.

LAPESA, R. (1991): Historia de la Lengua Española, Madrid, Gredos, $7^{a}$ edición.

MENÉNDEZ PIDAL, R. (1945): “El diccionario que deseamos”, prólogo a Vox, diccionario general ilustrado.

MeRKIN, R. (1983): “The historical/academic dictionary”, en R. R. K. Hartman et al., Lexicography: principles and practice, London, Academic Press, pp. 123-133.

Muller, C. (1977): Principes et méthodes de statistique lexicale, París, Hachette.

PENA, J. (1980): “La derivación en español. Verbos derivados y sustantivos verbales", Santiago de Compostela, Verba, Anexo 16, Secretariado de Publicacións da Universidade de Santiago.

POTTIER, B. (1973): Le langage, París.

Penny, R. (1993): Gramática histórica del español, Barcelona, Ariel, pp. 272-287.

QuemadA, B. (1972): "Lexicology and lexicography", Current Trends in Linguistics (ed. Th. A. Sebeok), vol. 9, Linguistic in Western Europe, La Haya-París, Mouton, pp. 395-475.

Real Academia Española de la Lengua (1973): Diccionario de Autoridades, 3 vols., facsímil de la edición de 1726-1739, Madrid, Gredos.

Real Academia Española de la Lengua (1992): Diccionario de la lengua española Madrid, EspasaCalpe.

Real Academia Española de la lengua (1960-): Diccionario Histórico de la Lengua Española, Madrid, vol. I: A-ALA y fascículos $11^{\circ}-21^{\circ}$ del segundo volumen: ALABA-Aonio.

REy, A. (1977): Le lexique: images et modèles. Du dictionnaire à la lexicologie, París, Armand Colin.

Rey-Debove, J. (1971): Etude linguistique et sémiotique des dictionnaires français contemporains, La Haya-París, Mouton. 
Rey-Debove, J. (1973): “Lexique et dictionnaire”, en B. Pottier (ed.): Le langage, París, pp. 82-109.

SalvadoR, G. (1985): “Lexicografía y geografía lingüística” en Semántica y lexicología del español, Madrid, Paraninfo, pp. 138-144.

Salvador, G. (1994): “EL DRAE”, en Actas del X Congreso de Lengua Española. Sevilla 1992, Madrid, Instituto Cervantes.

SECo, M. (1987): "El contorno en la definición", en Estudios de lexicografía española, Madrid, Paraninfo, pp. 35-45.

SeCo, M. (1987): "El nacimiento de la lexicografía moderna no académica”, en Estudios de lexicografía española, Madrid, Paraninfo, pp. 129-151.

SECo, M. (1991): Estudio introductorio a Real Academia Española, Diccionario de la lengua castellana reducido a un tomo para su más fácil uso, facsímil de la primera edición (1780), Madrid, Espasa-Calpe.

SECo, M. (1987): “La crítica de Cuervo al Diccionario de la Academia Española”, en Estudios de lexicografía española, Madrid, Paraninfo, pp. 178-193.

SECO, M. (1987): "Los diccionarios históricos”, en Estudios de lexicografía española, Madrid, Paraninfo, pp. 49-94

SECO, M. (1987): "Problemas formales de la definición", en Estudios de lexicografía española, Madrid, Paraninfo, pp. 15-34.

VV. AA. (1994): Aspectos de lexicografía contemporánea, Barcelona, Bibliograf.

ZquSTA, L. et al. (1971): Manual of lexicography, Praga-La Haya-París, Academia-Mouton.

\section{APÉNDICES}

\section{Apéndice 1. La estructura de la base de datos} guientes:

La estructura y características de la base de datos con la que se ha trabajado son las si-

LEMA: Campo en el que se recoge la entrada del diccionario.

CATEGORIA: Campo en el que se introduce la categoría gramatical de la palabra.

INF_DIACRO: Este campo incluye las marcas ant., desus. y p. us., es decir, la descripción diacrónica del lema que proporciona el DRAE92.

DEFINICIÓN: Se reproduce aquí la definición de los lemas que aporta DRAE92. La inclusión de este campo tiene un doble objetivo. El primero es facilitar la búsqueda de información sobre el corpus estudiado, puesto que, al tratarse de voces anticuadas o desusadas, ocurre a menudo que es necesario buscar la forma moderna del término para hallar información sobre la variante antigua. El segundo, es el de estudiar si existe algún cambio en el contenido, forma o número de las acepciones recogidas en el DRAE92 respecto al DRAE84.

CAMBIOS_84: Campo lógico que se incluye por motivos puramente estadísticos. El valor "T" (cierto) indica que en la entrada correspondiente del DRAE92 existen cambios respecto a la del 


\section{DRAE84.}

INF_DIA_84: Se especifican en este campo cuáles son, de existir, los cambios en la descripción diacrónica del lema en el DRAE92 respecto a la edición inmediatamente anterior. Si en el DRAE84 no se califica la voz como en la última edición, este campo reproduce la información que se daba en aquélla. El cambio puede consistir, también, en añadir información diacrónica a un vocablo que no estaba marcado como anticuado; en este caso, nosotros anotaremos No infformación diacrónica]. Finalmente, este campo puede aparecer en blanco; esto significa que se ha conservado en el DRAE92 la información que se daba en el DRAE84.

DEF_DRAE84: En algunos casos, los cambios que el DRAE92 presenta respecto del DRAE84 atañen a la definición. En tal caso, indicamos en este campo cuál es el cambio que se ha producido.

INF_AUT: Campo lógico con fines meramente estadísticos. El valor "T" (cierto) indica que la voz ya se recogía en Aut, lo cual permite estudiar el porcentaje de voces desusadas del DRAE92 que ya tenían entrada en Aut.

AuT: Si la voz ya se recogía en Aut., se reproduce en este campo la información que daba aquel primer diccionario académico. Se conservan las abreviaturas y convenciones de la edición.

INF_DCECH: Campo lógico en el que se indica si la información que aporta el $D C E C H$ es pertinente o no para el estudio que llevamos a cabo. El valor " $\mathrm{F}$ " (falso) puede, en consecuencia, tener dos lecturas: bien la voz no está recogida en este diccionario, bien sí lo está pero no ofrece ningún dato que ilumine el estudio realizado.

$D C E C H$ : Campo que recoge una síntesis de la información que el $D C E C H$ proporcionan sobre el lema tratado, siempre y cuando se considere pertinente para el estudio. Las abreviaturas que aparecen son suyas, y las obras citadas remiten a las ediciones que se manejan en dicho diccionario.

DIC_HIST: Siempre que exista en el DHLE una entrada para el lema tratado, se anota aquí la información cronológica que permite determinar cuál fue el período en que el vocablo estuvo vivo en la lengua. Esto se traduce normalmente en la notación de la primera y última documentación, que se abrevian como $1^{a} d o c$. y úl. doc. respectivamente; cuando sólo existe una documentación (es, por tanto, la primera y la última que se conoce), se anota doc[umentado] en... Alguna vez, también se mencionan documentaciones posteriores aparecidas en obras lexicográficas. Las abreviaturas se corresponden también con las utilizadas por el $D H L E$, y las referencias bibliográficas remiten a la bibliografía de la obra académica.

COTEJO: Consultadas las fuentes y seleccionados los datos que se consideraron pertinentes, y tras cotejar toda la información obtenida para concluir sobre la veracidad de las marcas académicas, se anota en este campo el resultado del análisis mediante el uso sistemático de ciertas convenciones. El hecho de haber usado este metalenguaje ha permitido efectuar recuentos automáticos, imprescindibles para poder llevar a cabo cálculos estadísticos.

ANT_2: La abreviatura ant. en el DRAE92 tiene dos significados. En su primera acepción, el término alude a las palabras que dejaron de usarse durante la Edad Media; en la segunda, hace referencia a las formas perdidas durante el Siglo de Oro de palabras que pervivieron con una forma distinta. El uso polisémico de anticuado genera una serie de ambigüedades que hacen prácticamente imposible determinar en algunas ocasiones cuándo dejó de usarse el vocablo. Aunque en el campo CoTEJo se estudia si la nomenclatura académica -incluida la segunda acepción de anticuado- se aplica con rigor, se ha creído oportuno abrir este campo ANT_2 en el que 
se marcan con "T" las voces afectadas por la segunda acepción del término, puesto que es ésta la que genera equívocos ${ }^{76}$.

NotAS: Si se juzga necesario, se ofrece en el campo NoTAS una explicación del contenido del campo Cotejo, o lo que es lo mismo, se da razón de cuáles han sido los datos que han permitido llegar a una conclusión en un sentido u en otro. Esto no ocurre nunca cuando la información cronológica del DRAE92 es, a la luz de los datos con que contamos, correcta77.

\section{Apéndice 2. El campo Coteso}

Al explicar cuál era la estructura de la base de datos que se había creado para facilitar la tarea que nos atañe, ya nos referimos brevemente al campo CoTEJo. Ahora nos proponemos exponer con detalle las convenciones en él utilizadas así como los criterios que han servido de guía en la delicada tarea de establecer cuándo la información diacrónica del lema que aporta la Academia es correcta; cuándo, a partir de las documentaciones de las fuentes consultadas, parece errónea, o cuándo, simplemente, podría mejorarse.

Asimismo, en este campo, se intentan precisar otras informaciones de distinta índole como, por ejemplo, si se está o no seguro del juicio emitido, si éste se basa exclusivamente en información extraída de Aut., si hay que añadir información dialectal al artículo, etc. Consecuencia inevitable de todo ello, es que la nomenclatura se complica ligeramente, y de ahí se deriva la necesidad de una explicación lo más diáfana posible.

A continuación se enumeran cuantas abreviaturas o combinaciones de ellas pueden hallarse en el campo COTEJo; asimismo, se ilustrará lo expuesto con algún ejemplo significativo.

\section{Nomenclatura utilizada:}

$b$ : Los datos que se poseen confirman la descripción cronológica que acompaña al lema.

$m^{78}$ : De acuerdo con los datos que se manejan, el DRAE92 ofrece una información errónea.

V.g.: la voz ahorría aparece en las páginas del DRAE92 como voz anticuada. Consultando las fuentes habituales, se descubre que, según el $D C E C H$, esta voz se documenta el año 1601 en A. Cabrera; a su vez, el $D H L E$ documenta el término por última vez en 1623. Si somos fieles a los criterios cronológicos establecidos, esta voz no es anticuada sino desusada, porque mantuvo su vigencia hasta el siglo XVII.

$? b / ? m$ : Un interrogante antepuesto a la nota $m$ o $b$ significa que con los datos que recogemos no es posible sacar conclusiones taxativas.

76 Todas estas voces deberían estar anotadas según los actuales criterios académicos con anticuadas. De suprimirse la segunda acepción de anticuado, lo cual simplificaría la consulta del diccionario, deberían constar como desusadas, porque las palabras que caen en desuso a partir del año 1500 ya no se considerarían anticuadas.

77 En el campo Cotejo aparecerá en estos casos, según se explica en el Apéndice 2, la nota $b$.

78 Algunas veces, el error en la anotación se halla en una sola acepción de la palabra, pero están correctamente anotadas las demás. Dado que la base de datos constaba de una entrada por lema, y no de una entrada por acepción, se ha marcado con $m$ el campo CoTEJo, a pesar de que alguna de las acepciones sí que estuviera bien anotada. Vid. supra. absolvimiento. 
?b suele significar que los datos obtenidos en el estudio no permiten desmentir ni confirmar la información cronológica del DRAE92.

V.g.: almadén es, según el DRAE92, palabra desusada. La última documentación que da el $D H L E$ data del siglo XVII (1615, Cervantes); luego, es desusada. Sin embargo, además de en Aut. está también documentada en varios diccionarios posteriores. Esto podría hacer pensar que es poco usada, aunque las documentaciones en las obras lexicográficas no son siempre fiables, dado que existe la posibilidad de que tomen como base de la lematización algún diccionario anterior.

Cuando carecemos de información sobre el lema, pero existen indicios de que la información cronológica del DRAE92 es incorrecta, aparece ?m.

V.g.: la voz desquito está recogida en el DRAE92 como anticuada. No hay información sobre desquito como participio de desquitar, pero sí de quito como participio de quitar (primitivo de desquitar). El hecho de que este último no se documente hasta el siglo XVI podría hacer suponer para desquito una primera documentación por los mismos años. De ser esto cierto, la voz no sería anticuada sino desusada, porque estaría documentada en el Siglo de Oro.

??: Cuando la investigación ha sido infructuosa y se carece por completo de información acerca de cuándo dejó de usarse el lema estudiado, se anota ??. En la mayoría de los casos, se trata de palabras no recogidas aún en Aut., no tratadas en el $D C E C H$, y que no aparecen en los volúmenes hasta ahora editados del DHLE.

$d$ : Independientemente del juicio emitido sobre la información cronológica, se anota $d$ cuando, en la entrada del lema, debería hacerse constar algún tipo de información dialectal que no aparece. Ésta puede referirse bien a la pervivencia del vocablo como dialectalismo en la lengua actual, bien al carácter dialectal de la voz cuando ésta existió. Sin embargo, cabe señalar que el presente estudio en este aspecto no ha sido ni mucho menos exhaustivo (no era éste su objetivo); por tanto, la ausencia de $d$ no tiene que significar necesariamente que la información dialectal no sea precisa sino, simplemente, que las fuentes consultadas no tratan este aspecto.

Con la abreviatura $d$, es posible encontrar las siguientes combinaciones ${ }^{79}$ :

$b d$ : La descripción cronológica del lema es correcta pero no se recoge el valor dialectal de la voz.

V. g.: agro2, está marcada por el DRAE92 como desusada, y lo es, en efecto, en castellano estándar, pues fue, según el $D C E C H$, la forma habitual hasta el siglo XVII. No obstante, sigue vigente como dialectal de Albacete.

md: No sólo es errónea la caracterización diacrónica de la voz, sino que además se omite información dialectal.

V. g.: desque aparece como anticuada. El DCECH informa que esta combinación de des más que siguió viva hasta el siglo XVI, lo que la convertiría en desusada. Además, en el siglo XIX todavía pervive con uso literario, y existe en la actualidad como variante dialectal en Asturias.

79 No hemos anotado en nuestro estudio ninguna voz con las abreviaturas ?bd e ?md, pero no existen motivos teóricos que impidan estas combinaciones. En el caso de que existiera significaría que no tenemos datos suficientes para sacar conclusiones taxativas, pero que los datos que poseemos sí nos dan noticia de una información dialectal de la que carece el DRAE92. 
??d: Aunque se desconoce la historia de la voz, se sabe que existe información dialectal que el DRAE92 omite.

V. g.: apaniaguar, palabra cuya historia documental ignoramos, existe hoy en día como variante dialectal en Salamanca.

*: Aunque nos hemos mostrado partidarios de aplicar un criterio cronológico estricto, hay que ser conscientes de que toda división, por arbitraria, falsea la realidad. Existen algunas'voces que cayeron en desuso en un lapso de tiempo que está a caballo entre el español medieval y el clásico, o entre este último y el español moderno. Ante estos casos, se ha anotado $b$ o $m$ según los criterios arriba definidos, pero añadiendo un asterisco que indica que la voz dejó de usarse en uno de estos períodos que podrían considerarse fronterizos. Se decidió añadir un asterisco a todas las palabras cuya última documentación conocida está comprendida entre 1485-1515 o entre 1785-1815. Este margen de tres lustros antes y después del cambio de siglo está de nuevo fijado arbitrariamente; no obstante, se ha hecho así porque suele considerarse que la diferencia entre dos generaciones es aproximadamente de quince años. Un intervalo de tres décadas es suficiente para que una voz, aunque siga viva en la generación anterior, haya quedado obsoleta ya entre los jóvenes de la generación siguiente y caiga, por tanto, en desuso.

$V$. g.: la palabra cras es en rigor anticuada, como la Academia indica, porque antes ya del siglo XVI perdió su vitalidad dentro del idioma. No obstante, indica el $D C E C H$, hay ejemplos que atestiguan el uso -ya restringido- del término durante el Siglo de Oro en frases proverbiales y anécdotas antiguas. Resumiendo, la voz dejó de utilizarse en el siglo XV pero pervivió como arcaísmo durante algunos años de la centuria renacentista.

a: Anteriormente se ha explicado que, cuando se ha manejado información procedente de fuentes diversas, damos siempre mayor credibilidad a las más modernas. Sin embargo, a veces la única información registrada es la de las autoridades citadas en Aut. En tal caso, se determina si la información del DRAE92 es o no correcta en función de la datación de las obras y autores citados por los primeros académicos, pero se añade siempre $a$ tras $b \circ \mathrm{m}$.

Las combinaciones en las que aparece la abreviatura a en el campo COTEJo son las siguientes:

ba: Aut., la única fuente que tenemos, ofrece unos datos que confirman la consideración de la voz que aporta el DRAE92.

V. g.: antevedimiento está marcada como anticuada. La única fuente con que se cuenta es Aut., que cita como autoridad a Alfonso X (las Siete Partidas).

ma: De nuevo Aut. es fuente única, pero ahora contradice de forma manifiesta la opinión de DRAE92 sobre la pervivencia de la voz en castellano.

V. g.: El DRAE92 considera aproar1 como palabra anticuada. En cambio Aut. ilustra el uso de este vocablo con una cita del Padre Alonso de Ovalle, que vivió y escribió en el siglo XVII; luego si existe documentación del Siglo de Oro, la voz debería clasificarse como desusada y no como anticuada.

?ba: Esta marca ?ba tiene la siguiente lectura: dado un lema, la única información que se tiene es Aut., el cual no contradice pero tampoco confirma la información cronológica de DRAE92.

V. g.: Derradamente es vocablo de poco uso para el DRAE92. Toda la información en nuestro haber es la documentación del siglo XVII que de la voz en cuestión proporciona Aut., con lo cual es imposible saber si la palabra es en efecto p.us. 